\title{
Information technologies in the training of evaluators of the Safe Hospital Program in Mexico
}

\section{Tecnologías de la información en la formación de evaluadores del Programa Hospital Seguro en México}

\section{Felipe Cruz-Vega', Juan C. Sánchez-Echeverría ${ }^{1 *}$, Hermes M. Cortes-Meza ${ }^{1}$, Jorge Loria-Castellanos ${ }^{1}$ and Erandy Montes de Oca-García ${ }^{2}$}

${ }^{1}$ Division of Special Projects in Health, Directorate of Medical Benefits; ${ }^{2}$ Hospital General 197. Instituto Mexicano del Seguro Social (IMSS), Mexico City, Mexico

\begin{abstract}
Objective: To describe the process for the training of evaluators of the safe hospital program in the use of ICT. Method: Descriptive observational study in which the participation in the new course of appraisers of the safe hospital program is analyzed. Results: 1323 participants registered of which 298 (18\%) passed; the average grade was 8.85. Conclusions: The Moodle type educational platform was useful for the training of the Safe Hospital Program. The criteria for student participation would have to be improved in order to increase terminal efficiency.
\end{abstract}

KEY WORDS: Distance education. Disasters. Safe Hospital Program.

\section{Resumen}

Objetivo: Describir el proceso para la formación de evaluadores del Programa Hospital Seguro centrado en el uso de las tecnologías de la información. Método: Estudio observacional descriptivo en el que se analiza la participación dentro del nuevo curso de evaluadores del Programa Hospital Seguro. Resultados: Se inscribieron 1323 participantes, de los cuales aprobaron 298 (18\%); la calificación media fue de 8.85. Conclusiones: La plataforma educativa tipo Moodle fue de utilidad para la capacitación del Programa Hospital Seguro. Se tendrían que mejorar los criterios de participación de los alumnos a fin de incrementar la eficiencia terminal.

PALABRAS CLAVE: Educación a distancia. Desastres. Programa Hospital Seguro.

\footnotetext{
Correspondence:

*Juan Carlos Sánchez-Echeverría

Paseo de la Reforma, 476

Col. Juárez, Del. Cuauhtemoc

C.P. 06600 , Ciudad de México, México

E-mail: juancarlosmarx@gmail.com
}

Date of reception: 01-03-2018

Date of acceptance: 06-04-2018

DOI: $10.24875 / C I R U E . M 18000036$
Cir Cir. 2018;86:209-214

Contents available at PubMed www.cirugiaycirujanos.com 


\section{Introduction}

The central axis of a health system that prides itself on protecting life is prevention. It is also the challenge faced by disaster management systems that seek to reduce risk to acceptable levels and thus contribute to populations' sustainable development. An ineffective response to a disaster generates high costs, in many cases incalculable, which translates into impoverishment of the population and stagnation in the development of countries and regions. Mitigation of the effects caused by disasters through the implementation of preventive actions is highly profitable'.

Latin America is the second region most affected by natural disasters. Sixty-seven per cent of its health facilities are located in risk areas. From 2004 to 2014, $61 \%$ of hospitals were affected by earthquakes, $17 \%$ by hurricanes, $14 \%$ by floods and $8 \%$ by health emergencies (epidemics, internal contamination and others). Nearly 24 million people were left without health care due to the impact on health services $(200,000$ people per unit) ${ }^{2}$.

In Mexico, the experience derived from the 1985 earthquake is the inflection point. The effects on hospital infrastructure, especially in Mexico City, led to the loss of medical care response capacity in highly complex units, since more than 5000 hospital beds were lost in less than 70 seconds. In addition to the high number of victims who perished in hospitals' collapsed structures, mortality was increased by a functional collapse of those units that remained standing. The determining factor was a health sector that was not prepared to respond in case of disaster ${ }^{3}$.

Among the reconstruction actions, initiatives were developed aimed at improving resilience, which is regarded as the capacity of a system, a community or a society exposed to a threat to resist, absorb, adapt, transform and recover from its effects in a timely and efficient manner, in particular by the preservation and restoration of its basic structures and functions through risk management ${ }^{4}$.

Under this precept, the Pan American Health Organization (PAHO) and the World Health Organization (WHO) developed the Safe Hospitals Against Disasters initiative.

In 1997, the Mexican Institute of Social Security started working together with $\mathrm{PAHO} / \mathrm{WHO}$ in order to find a reliable method to implement diagnostic and safety measures in hospitals, including the following ${ }^{5,6}$ :
- 2004: Resolution CD45.R8 urged member States to adopt the motto "Safe Hospitals Against Disasters" as a national risk-reduction policy.

- 2005: the Hyogo action framework for 2005-2015 was approved, where reference is made to "building the resilience of nations and communities to disasters".

- 2006: Mexico establishes the National Committee for the Evaluation, Diagnosis and Certification of the Hospital Seguro (Safe Hospital) Program.

- 2007: Hospitales Seguros is developed, which is a regional initiative to enable health facilities to resist the effects of disasters.

- 2008: a regional plan of action is developed for Hospitales Seguros, which was approved in resolution CD50.R15 of 2010, within its 2008-2012 strategic plan.

- The construction of new hospitals with a safety level that ensures their capacity to function in disaster situations is established as the goal for 2015.

- During the Third World Conference on Disaster Risk Reduction (2015-2030), the Sendai Framework was adopted, which is the successor instrument of the Hyogo Framework for Action, "Building the resilience of nations and communities to disasters".

The Hospital Seguro Program is a PAHO/WHO initiative and has a purely preventive nature. It is based on one tool, the Hospital Safety Index, which is obtained from a visual and objective evaluation by a select group of professionals related to the area of health.

To carry out this evaluation, the checklist proposed by $\mathrm{PAHO} / \mathrm{WHO}$ is used, which describes the criteria for each point to be graded as low, medium or high. Based on this assessment, a mathematical model is applied to obtain the hospital safety index. This evaluation protocol is systematized in four areas: geographical location, structural safety, non-structural safety and functional safety, which allows a comprehensive assessment of the facilities, as well as organization. Hospitals are classified by means of a certificate, according to their installed capacity to respond to emergencies or disasters.

In August 2007, the course "Evaluators of the Safe Hospital Program" was launched, which was taught online and consisted of 33 topics contained in 60 teaching hours. The dynamics consisted exclusively in the review of contents through videos, at the end of which an evaluation was carried out. In this modality, 21 training periods took place, with a registry of 
7474 participants, out of which 1792 (23.97\%) passed the evaluations ${ }^{7,8}$.

This evaluator training is highly complex, both administratively and logistically. From the variability in the application of the checklist, the teaching-learning process was identified not to be focused on the learner (future evaluator). In many cases, the process restricted the student to learning by imitation, mainly because the evaluator was not able to develop a feedback function, because the teaching method was based on a vertical model, similar to the classical model. Moreover, the possibility of sharing experiences with other evaluators of other institutions was observed to be absent, given that there wasn't any forum designated for this purpose.

At 8 years of its implementation, and considering both the updating of topics and contents and the growth and influence of the program, we consider it necessary to develop an improvement process intended to satisfy the educational and administrative needs in all its processes. For this, based on an analysis of the process carried out from April to June 2016, the relevance of the use of available technological tools was considered. Herein, we describe the experience of this implementation.

\section{Method}

The course was developed on a virtual platform (http://cvoed.imss.gob.mx/HospitalSeguro/login/index.php) of the Modular Object-Oriented Dynamic Learning Environment (Moodle) type, which contains a virtual environment for training, management and administration of resources and data.

The advantages that motivated us to use a Moodle-type platform include: a modular, multi-tool organization that contributes to the development and technological updating of the program; it allows access to contents from anywhere in the world; it facilitates collaborative work with other platforms (e.g., OPS); it offers the possibility of visualization from any electronic device, in addition to integrating a network of resources, information and tools for field evaluators; it has the option to be expandable in terms of resources and activities, according to the required needs, in addition to being intuitive and friendly, with controlled and safe access?

The course consisted of 12 modules: 1) Basic concepts; 2) National Civil Protection System; 3) National Health System; 4) Comprehensive risk management in Mexico; 5) Methodology for hospital evaluation; 6) Hospital Safety Index; 7) Geospatial identification of hazards and risks. National Atlas of Risks; 8) Structural safety; 9) Safety in non-structural elements; 10) Functional capacity; 11) Resilient hospital; and 12) Evacuation of hospitals with an emphasis on critical areas. In total, the course comprised 60 teaching hours.

Each topic was developed through electronic books with contents developed by experts in the field, and had conceptual and content validation by experts in disasters, emergencies and education.

Prior to the implementation of the course, the pilot test was carried out in 126 expert evaluators.

The training strategy considered:

- Review and analysis of instructions on each module.

- Reading and understanding of electronic book contents.

- Feedback activities.

- Pass the modular evaluations.

- Pass the final evaluation.

A key point was the online tutor, who was available 24 hours a day through chat and forums, to guide and to answer questions both on the topics and on issues of the platform.

Each of the institutions involved in the program proposed the participating students, and considered medical, paramedical, technical and administrative personnel, all directly involved in the planning and response to emergency or disaster situations.

\section{Results}

There were 1323 participants registered from different institutions of the country; out of them, $884(55 \%)$ had activity and 298 passed the course (18\%); 439 of registered participants (27\%) did not access the platform at any time. Students from 23 of the 32 States of the country passed the course (Table 1). Among the 298 students who passed, the grades ranged between 8.00 and 9.86 , with a mean of 8.85 . Of the 12 modules, the one with highest percentage of students who did not pass was Structural Safety (module 8). Total duration of the course was 8 weeks. Module 8 maintained an average of 9 days of activity. Main participation in forums was related to modules 4 and 8 .

\section{Discussion}

The objective is to strengthen preparedness for response in case of emergencies and disasters, and to manage for the response of institutions to be orderly, 
Cirugía y Cirujanos. 2018;86

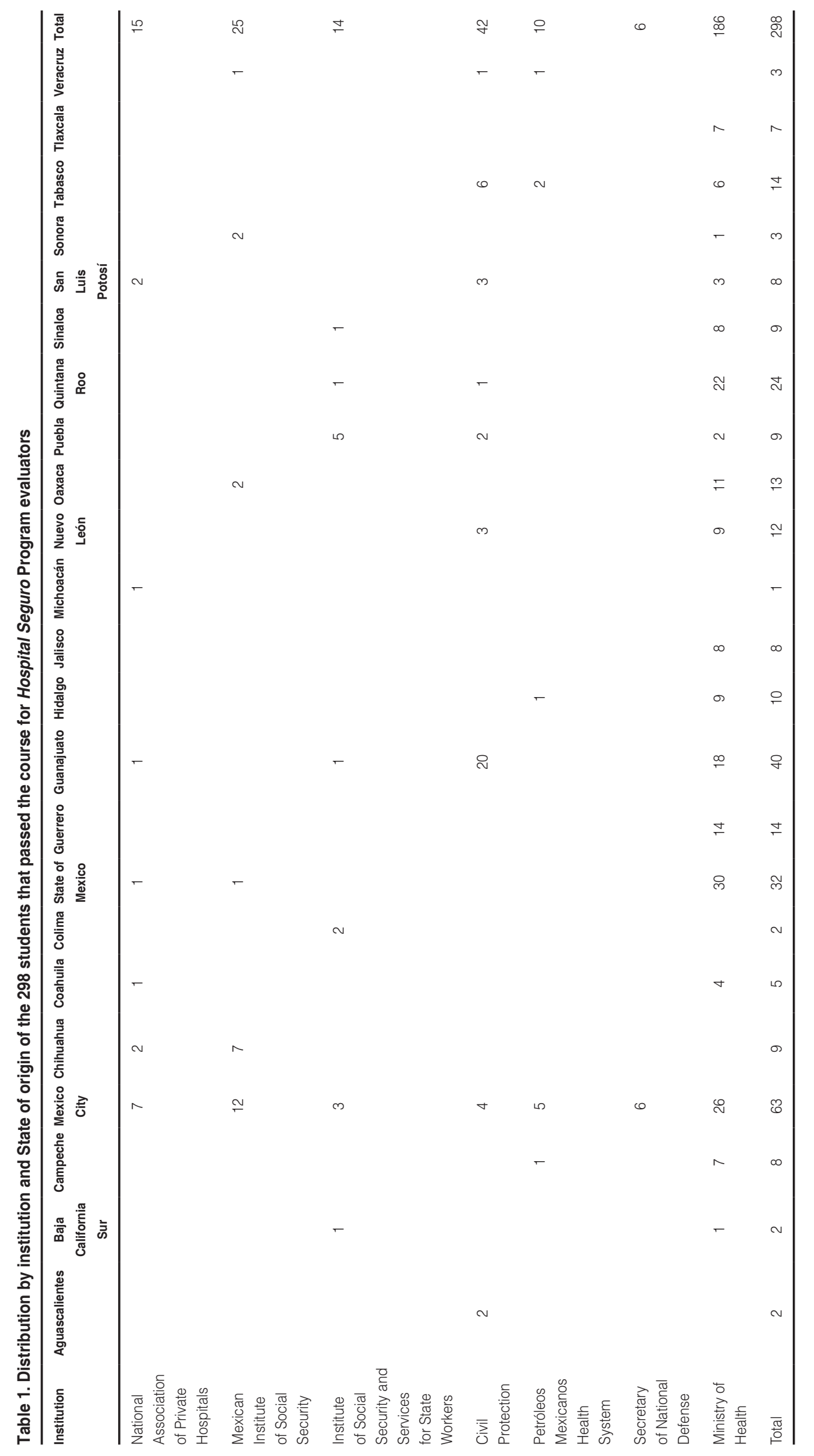


systematic and efficient. This, by virtue that there are studies that document, in several countries, that hospital units are usually not prepared to respond to an incident with massive casualties or to disasters, due to lack of knowledge, lack of plans for disaster and limitation of resources.

The 2017 version of the course for Hospital Seguro Program evaluators was developed based on a Moodle-type virtual education environment, provided free of charge as an open code program under the GNU General Public License. Anyone can adapt, extend or modify Moodle, both for commercial and non-commercial projects, without payment of licensing fees, and benefit from the cost/benefit, flexibility and other advantages of using Moodle. Currently, Moodle has more than 79 million worldwide users $^{7}$, among academic and business users, which makes it the most widely used learning platform in the world. This was one of the eligibility criteria, in addition to being a free software that provides a powerful platform with multiple tools for education, within a safe environment and with frequent updates ${ }^{9}$.

Surprisingly, more than one fourth of those who were registered did not access the course; on this point, we will have to find out if it was a lack of coordination with the institutions that proposed the participants or simply because of a lack of interest.

The objectives of the training environments include providing technical and technological support to the v2.0-2017 virtual course for the training of evaluators, as well as to provide continuous training and updating on topics related to the program evaluators, in addition to stimulating an environment of collaboration for the generation works and publications on emergencies and disasters.

The Technical Advisory Group of the National Committee for Evaluation, Diagnosis and Certification of the Hospital Seguro Program proposed that the new course for the training of evaluators for the Hospital Seguro Program should migrate to the Moodle platform, largely motivated by the many qualities it possesses and that would strengthen the process of distance education, with the following standing out:

- Modern, easy-to-use interface, designed to be responsive and accessible. The Moodle interface is easy to navigate on, both in desktop computers and mobile devices.

- It has a customizable board to show courses, messages and current tasks.
- Collaborative activities and tools. There are tools to work and learn together in forums, wikis, glossaries, database activities and much more.

- All-in-one calendar. The Moodle calendar tool allows keeping the academic or company calendar up to date, as well as delivery dates within the course, group meetings and other personal events.

- Convenient file management. It allows to drag and drop files from cloud storage services, including MS OneDrive, Dropbox and Google Drive.

- Simple and intuitive text editor. Text can be conveniently formatted and multimedia and images added with an editor that works with all Internet browsers and all devices.

- Notifications. When enabled, users can receive automatic alerts about new tasks and dates to deliver them, as well as make posts in forums and send private messages between each other

- Progress monitoring. Educators and learners can monitor the progress and the degree of completion with a set of options for monitoring individual activities or resources, as well as the course.

- Powerful administrative tools for the management of courses, users and contents.

The new course for the training of Hospital Seguro Program evaluators was completely redesigned on its contents in order to contextualize it within the framework of comprehensive risk management for multiple threats, following the recommendations of the Sendai Framework, which established that it is urgent and fundamental to anticipate the risk of disasters, plan measures and reduce it in order to more effectively protect people, communities and countries, their livelihoods, their health, their cultural heritage, their socio-economic assets and their ecosystems, thus reinforcing their resilience.

The 2017 update of the course tries to answer to the premise that it is urgent to strengthen and maintain a broader and more people-centered approach to disaster risk prevention, with disaster risk-reduction practices contemplating multiple threats and being multisectoral, inclusive and accessible in order for them to be efficient and efficacious. Therefore, the public and private sectors and civil society organizations, as well as the academic community and scientific and research institutions, should collaborate more closely and create opportunities for collaboration, and companies should integrate disaster risk into their management practices. 
In the new course, an approach to the topic "Comprehensive risk management in Mexico" was included, the purpose of which is to identify basic aspects of risk, as well as their comprehensive management, delving into the stages that make up said management and identifying the existing instruments.

This module discusses how disaster risk reduction is a profitable investment in the prevention of future losses. In addition, effective disaster risk management contributes to sustainable development.

Another topic that had not been contemplated in previous versions of the course is "Resilient Hospital", which is now included with the purpose to know the new concept of hospitals in a multiple threat context, with a focus on disaster risk management and reduction, with climate change being understood as a causal factor.

This topic deals with the strategy of smart hospitals and, according to Dr. Dana Van Alphen, regional advisor of the PAHO/WHO Area of Preparations for Emergency Situations and Relief in cases of Disaster, "the project will allow the development of a smart health facilities index that will accompany the national building standards and codes, in addition to a tool to support the implementation of mitigation measures in the face of climate change in the existing health facilities, as well as in those that are to be built". On the other hand, this project also proposes training activities and workshops to improve national capacities in order to achieve health facilities that are more prepared for climate change, with the strengthening of policies in this area, as well as with advice from the PAHO/WHO Advisory Group on Disaster Mitigation ${ }^{10}$.

This initiative will enable to reduce costs and accounts of public services, limit greenhouse gas emissions, improve air quality and accessibility in hospitals, as well as access to safe water and safety conditions. Therefore, training of the professionals responsible for hospital evaluations in Mexico on this topic was considered a priority within the framework of the Hospitales Seguros Program.

It is true that the heterogeneity of profiles may have influenced for some of the contents to be unknown or complex for the learner. However, this heterogeneity is precisely one of the strengths of the course and the program: the evaluation process itself includes administrative, technical, and clinical issues and even aspects directly related to the geophysical characteristics and the structural design and engineering of a medical facility. The intention is that the different disciplines and areas of knowledge these participants dominate are harmonized during their participation, planning for the response to disasters and the assessment thereof.

It is important to consider that the students who pass the course are contemplated as "evaluator candidates". To become an evaluator it is necessary to complete three internships, one within each area of the Hospital Seguro Program (Structural Safety, Non-structural Safety, Functional Capacity), with the purpose to both reinforce knowledge and verify that it can be extrapolated to reality. At this moment, the admitted students are doing their internships throughout the country, and the results will be the subject of another study.

\section{Conflicts of interest}

The authors declare not having any conflicts of interest.

\section{References}

1. Bitrán DB. El impacto de los desastres naturales en el desarrollo económico. 1992. (Consultado el 19 de diciembre de 2017.) Disponible en: http://www.eird.org/esp/cdcapra/pdf/spa/doc2194/doc2194-contenido.pdf.

2. Bello O, Ortiz L, Samaniego JL. La estimación del efecto de los desastres en América latina, 1972-2010. ONU-CEPAL; 2014.

3. Cicero Sabido R, Padua Gabriel A, Rodríguez Martínez H, Toledo B, Yáñez Villar A. Efectos del terremoto del 19 de septiembre de 1985 en el Hospital General de la Ciudad de México. Algunas consideraciones. Salud Pública de México. 1986;28:521-6.

4. UNISDR. Terminología sobre reducción del riesgo de desastres. (Consultado el 16 de noviembre de 2017.) Disponible en: http://www.unisdr. org/files/7817_UNISDRTerminologySpanish.pdf.

5. Secretaría de Salud (México). La calidad de la atención a la salud en México a través de sus instituciones: 12 años de experiencia. México: Secretaría de Salud; 2012.

6. UNISDR. Marco de Sendai para la reducción del riesgo de desastres 2015-2030. (Consultado el 16 de noviembre de 2017.) Disponible en: https://www.unisdr.org/files/43291_spanishsendaiframeworkfordisasterri.pdf.

7. Cruz-Vega F, Loría-Castellanos J, Hernández-Olivas IP, Franco-Bey R, Ochoa-Ávila C, Sánchez-Badillo V. Experiencia en capacitación en emergencias de la División de Proyectos Especiales en Salud, Instituto Mexicano del Seguro Social. Cirugía y Cirujanos. 2016;84:127-34.

8. Loria-Castellanos J. Utilidad de una plataforma educativa en línea para la especialidad de urgencias médico-quirúrgicas en México. Rev Panam Salud Pública. 2014;35:374-9.

9. Moodle. Acerca de Moodle. (Consultado el 10 de noviembre de 2017.) Disponible en: https://docs.moodle.org/all/es/Acerca_de_Moodle.

10. El proyecto Hospitales Inteligentes mejorará la infraestructura sanitaria en el Caribe. (Consultado el 14 de diciembre de 2017.) Disponible en: http://www.paho.org/disasters/index.php?option=com_content\&view=article\&id=1700:smarthospitals\&ltemid=1178\&lang=es. 